DOI: https://doi.org/10.11144/Javeriana.upsy16-5.fvlr

\title{
Una forma de vida laboral en Santiago de Chile: relatos de mujeres otavaleñas*
}

Way of Working Life in Santiago de Chile: Stories of Otavaleñas Women

Recepción: 11 Junio 2017 | Aprobación: 28 Agosto 2017

Lorena Paola Pérez Azúa a

Movimiento Acción Migrante, Chile

ORCID: http://orcid.org/0000-0001-7345-3666

a Autora de correspondencia. Correo electrónico: lorenazua@gmail.com

Para citar este artículo: Pérez Azúa, L. P. (2017). Una forma de vida laboral en Santiago de Chile: relatos de mujeres otavaleñas. Universitas Psychologica, 16(5), 1-14. https://doi.org/10.11144/Javeriana.upsy16-5.fvlr

\section{RESUMEN}

Chile constituye un polo de atracción para inmigrantes trabajadores/ as, provenientes principalmente de América Latina y el Caribe en un contexto de crisis mundializada. Bajo este escenario, el presente artículo busca comprender los significados que otorgan las mujeres otavaleñas, indígenas ecuatorianas, al proceso migratorio y vida laboral en Santiago de Chile. Se realizaron acompañamientos, observación y entrevistas cualitativas de trayectorias sociales vinculadas a la práctica laboral. Los hallazgos sugieren que si bien la movilidad es motivada por mejorar su situación económica, los trayectos sociales que viven en Chile las confrontan a una existencia precaria y conflictiva que abordan mediante estrategias individuales y sociales. Esto es, a partir de la incorporación de su cultura y los recursos valóricos con los que cuentan.

Palabras clave

Mujer otavaleña; migración transnacional; comercio informal; criminalización.

\section{ABSTRACT}

Chile is a pole of attraction for immigrant workers, coming mainly from Latin America and the Caribbean in a context of globalized crisis. Under this scenario, this article seeks to understand the meanings granted by Otavaleñas women, indigenous Ecuadorians, to the migratory process and working life in Santiago de Chile. In order to do that, we accompanied, observed and did qualitative interviews of social trajectories related to their labor practice. The findings suggest that although mobility is motivated by improving their economic situation, the social paths that live in Chile confront them to a precarious and conflictive existence, which they approach through individual and social strategies. This is, from the incorporation of their culture and their valuable resources. Keyword: Otavaleña; transnational migration; informal commerce; criminalization. Introducción

Keywords

Otavaleña; transnational migration; informal commerce; criminalization.

\section{Introducción}

En la actualidad, la migración en Chile es un fenómeno de reflexión en diferentes espacios: académico, público, político y mediático. Esta repercusión se debe al crecimiento de 
población inmigrante desde hace más de una década (Cano \& Soffia, 2009; Martínez, 2003; Mora, 2009; Stefoni, 2004, 2011; Tijoux, 2011). Aunque se dispone de una extensa literatura, se observan limitaciones puesto que el fenómeno aparece como nuevo en el país y hay una amplia diversidad de grupos inmigrantes.

En la última década, la inmigración regional hacia Chile ha aumentado considerablemente (Cano \& Soffia, 2009; Martínez, 2016; Stefoni, 2004; Stefoni, Acosta, Gaymer, \& CasasCordero, 2008). A partir de una estimación realizada por el Departamento de Extranjería y Migración (Cabieses, Bernales, \& Mcltyre, 2017) con datos estadísticos propios y con proyecciones del censo 2002, se estima que residen en Chile 441.529 personas de otros países, lo que representa el $2.7 \%$ de la población total. La inmigración en el país se ha cuadriplicado desde 1982 hasta la actualidad, lo que se atribuye a la estabilidad económica del país que se relaciona con las oportunidades de empleo, el incremento de salarios y a la reducción de la pobreza (Contreras, Ruiz-Tagle, \& Sepúlveda, 2013; Organización Internacional para las Migraciones [OIM], 2012). Al factor económico se sumará, por un lado, la estabilidad política con el retorno a la democracia (Machín, 2011) y, por otro lado, que los países que protagonizan el reciente crecimiento poblacional se convierten en estados expulsores por problemas estructurales en ámbitos sociales, políticos o culturales.

El aumento de flujos migratorios implica la incorporación segmentada al mercado laboral. La precariedad está presente en el espacio laboral sin importar la calificación de la persona inmigrante, en la cual su condición laboral estará atravesada por factores discriminatorios vinculados al género, clase social, etnia u origen. Así, las actividades a las que se incorporan las inmigrantes serán por lo general de menor calificación, baja remuneración, altos niveles de riesgo y extensas jornadas. En suma, la inmigración en Chile se caracteriza, entre otras cosas, por insertarse en espacios de servicios o trabajos informales.

\section{La migración ecuatoriana en Chile}

Sobre la migración ecuatoriana en Chile se conoce que entre 1992 y 2002 su población ha aumentado en un $314 \%$ (Martínez, 2003) y en la actualidad, según estadísticas del Departamento de Extranjería, hay 22.918 personas que representan el $5.1 \%$ del total de la población inmigrante. Se hallan dispersos en el territorio chileno y un $64 \%$ vive en la región Metropolitana (FUNDACIÓN CREA, 2015) y en las regiones del Maule, Atacama y $\mathrm{O}^{\prime}$ Higgins (Machín, 2011).

Ecuador configura un país con un perfil emigratorio que se explica por dos momentos históricos: el primero hace referencia a la crisis del comercio de paja toquilla que se inicia a principios de 1950 y se extiende hasta 1960. La migración en este período fue principalmente masculina y se dirigió a Estados Unidos, lo que posibilitará el establecimiento de los siguientes flujos migratorios (Villamar, 2004). Un segundo momento surge durante la crisis económica, social y política de finales de los noventa (Camacho, 2010; Ramírez \& Paul, 2005) que generó una masiva salida de ecuatorianos al exterior. En otro punto, la inmigración ecuatoriana en Chile es reciente, con un promedio de 6.7 años de residencia, en la que más del $60 \%$ están ocupados y gran parte se ha insertado en el sector público de la medicina. Asimismo, un $30 \%$ de la población ecuatoriana corresponde a trabajadores por cuenta propia (Machín, 2011) que vive situaciones menos privilegiadas que los médicos o profesionales.

De acuerdo con Stefoni y colaboradores (2008) se identifican algunas agrupaciones de población indígena otavaleña cuyas sus características socioeconómicas son, por lo general, menos favorables. Por ejemplo, viven una incorporación segmentada al mercado laboral y muchas veces se incorporan al sector informal como comerciantes ambulantes. 


\section{Otavaleños en Chile: una migración transnacional}

Los otavaleños representan un pueblo que pertenece a la nacionalidad kichwa que se establece en la Sierra andina norte del Ecuador. $\mathrm{Su}$ historia relata escenarios de sobrevivencia frente a la imposición colonial, cuyos rezagos se transforman en nuevas formas de dominación del blanco-criollo (Meisch, 2002). En cuanto al desarrollo laboral y económico, la población otavaleña combina actividades que varían con el aumento y especialización de producción artesanal, puesto que surgen diversas formas de comercialización. Una de ellas, la más fuerte, será la transnacional, que representa la figura del indígena de la modernidad, población kichwa-otavaleña que se define a sí misma como "ciudadanos del mundo" (Maldonado, 2004). El caso otavaleño es ejemplo de una temprana forma de migración transnacional por el constante cruce de fronteras de sus protagonistas, definida por lo simultáneo -estar allí y acá-. Asimismo, porque sus procesos migratorios se caracterizan por el hecho de que "hoy en día los migrantes desarrollan redes, actividades, modos de vida e ideologías que conectan y cubren sus lugares de origen con las sociedades receptoras" (Ruiz, 2005, p. 104).

Los estudios que destacan en este fenómeno transnacional se construyen en la academia norteamericana, en especial los estudios de Basch, Glick Schiller y Szanton-Blanc (en Lafleur \& Yépez, 2014; Ruiz, 2009). Estas autoras definen transnacionalismo como "los procesos en los cuales los migrantes forjan y sostienen múltiples hilos de relaciones sociales que conectan a las sociedades de origen con las de destino" (Basch et al., 1994, p. 7 en Lafleur \& Yépez, 2014). Lo que se plantea en esta conceptualización es la interconexión social y cultural (Suárez, 2008), forjada en las redes sociales, en el sentido de apoyar los procesos migratorios, ya que representa reducción de costos económicos y psicológicos. En este punto, dichas redes enlazan a las personas migradas con sus países de origen (Portes \& DeWind, 2006).
La migración otavaleña constituye una práctica que, en el sentido transnacional descrito por Suárez (2008), cruza fronteras geográficas, culturales y políticas, eludiendo la idea natural que los Estados forman sobre las fronteras. No obstante, este proceso no se libra del sometimiento de los efectos de control, sanción y transformación de las fronteras y las aduanas, lo que ha modificado su temporalidad cíclica de la movilización. Los países de destino continúan siendo variados, pero los estrechos márgenes del espacio social del grupo de otavaleños se mantienen a pesar de las distancias y permiten que se compartan las experiencias de los viajes, se conozca en qué lugares es mejor trabajar y en cuáles no. La tecnología comunicativa, además del mayor acceso a los medios de transporte, fomenta y amplía las conexiones transnacionales. Las diversas estrategias que sostienen a la comunidad transnacional otavaleña (Portes, Guarnizo, \& Landolt, 2003) se organizan, entre otras cosas, a partir del comercio transnacional constituido como una economía étnica en los países de destino.

La significación tradicional y doméstica del trabajo de los kichwa otavalossufre cambios durante la reestructuración capitalista en Latinoamérica (Antunes, 2009), pues el orden neoliberal "ha precarizado aún más las condiciones laborales de la población indígena porque han reforzado la informalidad que las caracteriza" (Pedone, 2004, p. 33). Para ahondar a detalle el panorama laboral, en el siguiente apartado se describe conceptualmente el campo del trabajo.

\section{El trabajo y condiciones del trabajo informal en América Latina y en Chile}

Las nuevas formas de trabajo se ubican históricamente durante la reestructuración capitalista, durante la cual ocurre una disminución de la fuerza de trabajo humana para reemplazarla con maquinaria. El trabajo formal sufre cambios a propósito de las nuevas tecnologías y la nueva manera de organización. Como resultado, aumentan los índices de 
desempleo, se debilitan los lazos y se produce una erosión de los reglamentos y convenios entre empleados y empleadores. Al mismo tiempo, se evidencia la precarización de un sector del mercado de trabajo, identificado como sector informal, trabajo parcial, subcontratación, entre otros (Antunes, 2009; Da Rosa, Chafin, Baasch, $\&$ Soares, 2011; De la Garza, 2000).

En la realidad latinoamericana, junto a los desafíos del desarrollo del siglo XX, se relacionan patrones estructurales que caracterizaron la transición de la sociedad de un antiguo régimen a otro moderno. Se incorporan nuevos tipos o formas de trabajos. El trabajo informal se encuentra fuera de la economía oficial, al margen de la fiscalización, tributación y regulación, lo que disminuye el gasto de las empresas privadas y del Estado, configurando un engranaje necesario para el funcionamiento capitalista (Portes \& Haller, 2004). Los matices de este campo laboral varían desde trabajos ambulantes callejeros, hasta los call centers. Así, en esta región se presentan al menos 130 millones de personas trabajando en condiciones de informalidad (Organización Internaciónal del Trabajo [OIT], 2016). Los datos de la OIT (2014) revelan que "el quintil más pobre tiene una tasa de empleo informal de $72.5 \%$, mientras que el quintil más rico de $29.8 \%$ " (p. 11). Esta evidente desigualdad da cuenta de la relación entre el modelo informal y la pobreza en la región.

La actividad laboral ambulante no representa una opción en sí, sino que configura una salida frente a la falta de alternativas que brinden el mínimo de condiciones para vivir. La mujer trabajadora, bajo esta misma perspectiva, estaría empujada a trabajar de esta manera para complementar la renta familiar. Además, la característica laboral de lo ambulante calzaría perfectamente con sus condiciones, ya que se compaginarían las funciones de madre con el mercado de trabajo. Asumiendo la lógica anterior, se observa que el trabajo ambulante callejero representa una ocupación ligada a la subsistencia que, por lo general, se caracteriza por el comercio de bienes o servicios a pequeña escala (Ghersi, 2005). En este sentido, se incorpora fácilmente a un segmento precario del mercado del trabajo, donde los ingresos dependen no tanto de la productividad, sino más bien de la capacidad de alcanzar un mercado específico rentable.

En la ciudad de Santiago, las instituciones municipales regulan el trabajo callejero al otorgar permisos y patentes para el uso permanente o temporal de los espacios públicos o a través del arriendo de kioscos. Sin embargo, también se determina qué productos se pueden vender y cómo venderlos y también se dispone de una instancia tributaria que fiscaliza la actividad comercial que, para el caso chileno, corresponde al Servicio de Impuestos Internos (SII). De acuerdo al control de las instituciones en mención, se puede determinar si el trabajo callejero es regular o irregular. Las estructuras regulatorias contemplan las siguientes sanciones: a) el comiso de las mercaderías y de las instalaciones, efectuado por Inspectores Municipales y Carabineros, b) la multa que varía de 0.5 a 1 Unidades Tributarias Mensuales (UTM: unidades de cuenta usadas en Chile para efectos tributarios y de multas) fijada por el Juzgado de Policía de Santiago. No obstante, según la Ordenanza Municipal $\mathrm{N} .^{\circ}$ 59, esta multa puede ampliarse al rango de 1 a 3 UTM (Municipalidad de Santiago, 2009).

En este contexto, surge indispensable explorar los significados de la población que ejerce el trabajo informal, fundamentalmente callejero, en un entorno de alta complejidad y sanción. De este modo, la presente investigación se orienta a conocer los significados que otorgan mujeres otavaleñas inmigrantes en Santiago de Chile a sus procesos migratorios y a su forma de vida laboral.

\section{Método}

Diseño

El tipo de estudio es exploratorio-descriptivo, de carácter cualitativo. Es exploratorio porque indaga la significación que otorgan las mujeres otavaleñas a su proceso migratorio y a su vida laboral, y propone una temática no desarrollada profundamente en el contexto 
chileno. Representa un estudio descriptivo puesto que caracteriza y relaciona un sentido diferente sobre la inmigración, a partir de los significaciones que las agentes otorgan a la experiencia transnacional y laboral vivida en Chile.

\section{Participantes}

Inicialmente, se enfatiza que la población otavaleña concentra, como forma de vida, la cuestión de la migración comercial, lo transnacional, el comercio informal ambulante y la relevancia de la participación de la mujer (Kyle, 2001; Maldonado, 2004; Ruiz, 2009). De este modo, las participantes representan a mujeres mayores de edad, otavaleñas, dedicadas a la actividad del comercio informal, que viven en la ciudad de Santiago. Por lo tanto, el muestreo realizado es intencional. A pesar de que es importante indagar sobre el estatus legal por configurar un factor de mayor vulnerabilidad de las personas inmigrantes en Chile, el objetivo no es abordar la condición de regularidad de estas mujeres, por lo que este aspecto no constituye un criterio de exclusión o inclusión. La forma de exploración del terreno se sustenta en la proximidad y cercanía de la investigadora, quien además de pertenecer a la comunidad ecuatoriana, ha establecido contactos previos con colectivos de otavaleñas, quienes se ofrecieron como contactos iniciales e informantes claves. A su vez, se configuraron dos estrategias de terreno: la primera consistió en movilizarse a ferias artesanales de la ciudad y las calles en donde se observa comercio informal, para establecer diálogo con mujeres otavaleñas y luego explicar sobre los objetivos de la investigación. En este punto, se preguntó a las posibles participantes si presentaban interés en colaborar $y$, de ser afirmativa la respuesta, se solicitó el contacto telefónico. La segunda forma de exploración correspondió a la visita a instituciones que se relacionan con la población ecuatoriana en Chile. A partir de estas estrategias, el tamaño de la muestra participante es de ocho mujeres.
Para indagar sobre el sentido que mujeres inmigrantes otavaleñas le otorgan a su proceso migratorio y a su forma de vida laboral en Santiago, recurrimos a dos dispositivos etnosociológicos, esto es, la observación participante de las trayectorias urbanas, los lugares de trabajo, las interacciones cotidianas y las dificultades en este recorrido de la vida laboral de ocho mujeres inmigrantes otavaleñas en Santiago. Otra herramienta la configura la entrevista en profundidad, que responde al interés por conocer, describir y analizar la significación del relato de dichas mujeres, es así como se aplica una entrevista de aproximadamente 45 minutos por mujer.

Nuestro enfoque de análisis será abordado desde la mirada de Pierre Bourdieu (2001), quien reconoce que el discurso está configurado por formas de percepción y expresión que han sido interiorizadas, además nos dirá que se construye y rige desde una estructura que será la encargada de censurar o validar. La censura no es ajena a la estructura del campo, más bien representa sanciones que surgen desde el mismo campo y funcionan como un mercado, en el sentido de que se imponen precios a las diferentes modalidades de expresión.

El análisis está pensado en un contexto social, histórico y en situaciones particulares que varían de un relato a otro, hallando puntos de encuentro y desencuentro, que serán señalados desde los propios decires, aunque también desde la forma en que se los dice, de las censuras, de los silencios, de quienes están ausentes en el relato y de lo que se reprime.

Para el análisis de discurso, debemos tomar en cuenta las relaciones de fuerza simbólicas que se establecen en el grupo social -que impide u obliga a hablar-y "las leyes mismas de formación del grupo (por ejemplo, la lógica de expulsión consciente a inconsciente) que funciona como una censura previa" (Bourdieu, 2001, p. 110). En este análisis, se contempla observar también lo objetivo, analizar el campo social que nos compete -comercio transnacional- primero, pensar el campo en relación con el campo del poder. En segundo lugar, "establecer la estructura objetiva de las relaciones entre posiciones 
ocupadas por los agentes o instituciones que compiten dentro del campo en cuestión [y tercero] analizar los habitus de los agentes" (p. 70), esto es, las disposiciones adquiridas en determinadas condiciones socioeconómicas.

\section{Resultados}

Desde los relatos de las mujeres otavaleñas entrevistadas se entiende cómo se producen las categorías planteadas -mujer, inmigrante, indígena y trabajadora- y se asumen como construcciones sociales, parte de una realidad y tiempo social, no atribuibles a ningún hecho esencial o natural. Los kichwas-otavalos se presentan como un ejemplo que históricamente ha superado las condicionantes de vulneración, a partir de estrategias construidas desde recursos étnicos articulados en lo que se entiende como comunidad transnacional con múltiples vínculos con el lugar de origen y el de destino (Kyle, 2001; Ordóñez, 2008; Ruiz, 2009). La práctica transnacional otavaleña es una temprana diáspora comercial realizada en constante movilidad y en relación con el apoyo sociofamiliar del país de origen que se caracteriza por un nivel de institucionalización bajo comunidad transnacional "desde abajo"- en el sector económico y sociocultural, por la carga identitaria de sus trayectorias comerciales y su cultura (Portes et al., 2003). A pesar de esto, es imperativo reconocer este fenómeno en un periodo diferente de la economía mundial y en el contexto en el que se sitúe.

En Chile, las actividades laborales de los y las otavaleñas se desarrollan en ferias artesanales y en la calle como comercio ambulante. En este sentido, a pesar de los recursos sociales y culturales con los que se estructura su migración y práctica económica, el nivel en el que se encuentran es de sobrevivencia, debido a los riesgos y precariedades que se derivan del trabajo informal y, peor todavía, ambulante.

\section{"Es como que te llevan la suerte": la criminalización del comercio callejero}

En la ciudad de Santiago, las posibilidades para obtener un permiso de trabajo ambulante son casi nulas, por no decir imposibles. En este sentido, la institucionalidad política estaría fomentando la irregularidad del trabajo callejero y, consecuentemente, su criminalización, pero en ningún momento su erradicación. Frente a esta realidad, la única salida para las mujeres otavaleñas entrevistadas que se dedican a esta actividad es usar el espacio público para el comercio callejero, por lo que serán criminalizadas (Figura 1). Esto configura el principal riesgo que atraviesa su vida laboral.

\section{Figura 1}

La criminalización, campo de poder que domina la práctica laboral.

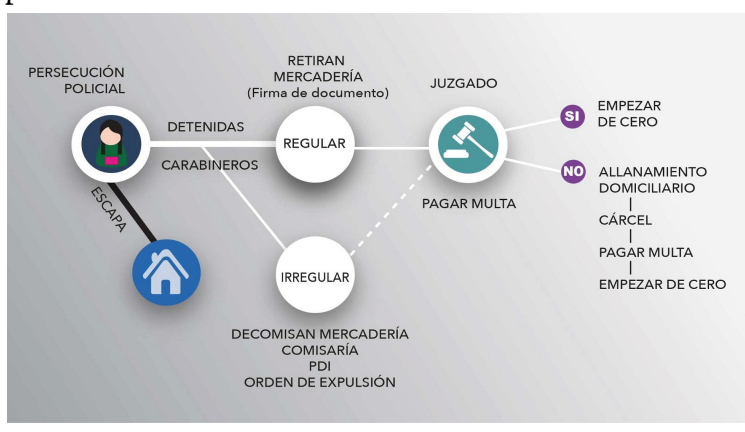

Fuente: elaboración propia a partir de los relatos de las mujeres entrevistadas.

Una vez que las mujeres llegan al lugar de trabajo, "tiran el paño": esta acción performativa, en el sentido de Goffman (1963), da inicio al comercio callejero, a la interacción con vendedores y clientes, pero también a la incertidumbre sobre los posibles enfrentamientos que se dan con las fuerzas que regulan su práctica laboral.

Cuando tú te comienzas a colocar, ya no estás tranquila, siempre estás nerviosa, viendo para acá, viendo para allá, viendo para acá, viendo para allá. (Johana, 30 años, Enero 13 de 2015)

Se establece la relación descrita con el campo de poder. De este modo, llevar a cabo el proceso de intercambio comercial no dependerá 
únicamente de la venta, sino se añaden los niveles de control con los que se encuentren en el microespacio laboral.

Un día normal de mi trabajo es cuando no molestan mucho los carabineros, igual cuando hay harta venta, cuando hay venta, se vende cien mil, setenta mil, ochenta mil, pero cuando a veces, igual deja tranquilo y hay venta, cuando compran harto. En cambio, así [...] cuando (vienen) los carabineros, no se puede vender. (Matilde, 23 años, marzo 13 de 2015a)

La comercialización de los productos en la calle es una actividad que, de acuerdo a Bourdieu (1995), se desarrolla en un espacio social. En este microcosmo, lo relacional se establece como una red de posiciones definidas por su existencia objetiva y la determinación que le den quienes las ocupan. En el campo laboral ambulante, las posiciones están dominadas por las instituciones -encargadas de la regulación- y por los/las agentes -vendedoras, clientes, transeúntes, entre otros-. En este punto, se desarrolla el análisis de lo relacional entre las agentes (mujeres comerciantes) y las instituciones estatales (que criminalizan esta actividad), puesto que la configuración del comercio ambulante informal se propicia en un campo de poder institucional (estructural), que haciendo eco de la política reguladora del sector público y económico, censura el tipo de actividad informal ambulante.

De esta manera, es importante identificar que en los relatos se rescatan dos tipos de relaciones entre estas posiciones: una objetiva y otra subjetiva. La primera se refiere a la relación de fuerza dominación/subordinación entre las mujeres y los agentes que operan la ley reguladora. La posición subjetiva, en cambio, muestra cómo las comerciantes entrevistadas y agentes activas en el campo han constituido diferentes capitales que permiten la convivencia con la fuerza que las reprime.

Cuando trabajamos en la calle, a lo que una está expuesta es a eso, a los carabineros, a que nos maltraten algunos, claro no nos pegan, sin embargo, psicológicamente, a veces nos insultan, nos dicen, cualquier cosa, no nos tratan bien y algunos no, algunos son comprensibles. Como hay de todo, y nos quitan la mercadería también, hay algunos que no quieren devolvernos nada, nada, nada, nos quitan todo. Hay algunos que sí nos devuelven, aunque sea un poco, entonces sí, una se ha encontrado a lo largo de estos años con diferentes tipos de carabinero, diferente tipo de personas, como discriminantes, y algunos que nos defienden también, que son personas buenas, o sea, de todo se ha encontrado acá. (Hortensia, 33 años, Junio 01 de 2015)

El Estado y la constitución de la estructura del campo de poder, que regula el campo laboral de las entrevistadas, tiene efectos sobre las trayectorias sociales y subjetivas de estas mujeres. En este punto, ellas definen el trabajo callejero a partir de la experiencia de persecución que viven en lo cotidiano y los efectos de esto sobre sus particularidades.

Ha sido un poco arriesgado, muy arriesgado, sacrificado se podría decir, pero así que digamos tanto sufrimiento así, no, pero sí es muy complicado el hecho de que si te agarran los carabineros, de lo poco que ganas se va todo ahí, y es como una frustración de que estás bien, estás ganando pero cuando te agarran los carabineros se te llevan todo, es como que te llevan la suerte. Entonces como que tienes que empezar de nuevo, y eso ha sido como nuestro ciclo de vida aquí, estamos recién empezando a ganar y vienen los carabineros y nos quitan y todo se va ahí, y así estamos viviendo como al día. (Johana, 30 años, Enero 13 de 2015)

Durante las entrevistas, las mujeres otavaleñas dan un espacio importante a la relación de su trabajo con el campo de poder. Los tonos de tristeza y frustración acompañan al relato que cuenta su posición como criminales en la estructura del sector informal, lo cual detalla pérdidas materiales y simbólicas.

Los carabineros vienen, nos cogen, nos quitan la mercadería, eh, nos llevan a la cárcel, y nos ponen multa, y nos quitan todo, y después de un tiempo, nos piden la dirección y todos los datos. Viene a la casa una citación, diciendo usted está citado acá al juzgado y tiene que presentarse, y si no se presenta, vienen en busca de nosotros, de la persona que le buscan y si le encuentran le 
llevan no más a la cárcel. Tiene que pagar sí o sí, o sino tiene que pagar con noches de reclusión ahí. (Rita, 29 años, Febrero 15 de 2015)

De lo observado en el campo, los agentes policiales chilenos -carabineros- asumen varias formas para controlar el trabajo ambulante. Una de ellas consiste en ir camuflados como civiles y comprar algún producto, aunque se observan otras más agresivas y recurrentes que llegan al lugar en donde están los/las vendedores/as, con los autos-retenes o en motos. Cuando utilizan este último, como medio de detención, pisan el pañuelo y los/las vendedores/as no pueden escapar.

A veces igual, cuando vienen las motos, más que todo las motos, es lo que se tiran más, se suben la vereda, la acera y vienen directamente, entonces más que todo a ellos hay que tener más cuidado, porque vienen más rápido pues, no hay tiempo de estar agachándose mismo, hasta estar agachándose, las motos ya están encima de nosotros, sí. (Matilde, 23 años, Marzo 13 de 2015)

Después de la detención en el lugar, los agentes policiales solicitan la cédula de identidad para procesar el documento del decomiso de la mercadería, el cual se supone que es un inventario que se establece como recibo para recuperar la mercadería. Además, reportan al Juzgado Policial de Santiago para que procesen la citación correspondiente para pagar la multa.

No podemos hacer nada, ni siquiera sabemos qué hacen ellos con nuestra mercadería, lo que nos dan es un papelito que dice que tiene que presentarse para tal fecha, y nos presentamos, eso es en el juzgado y nos dan donde tenemos que ir y supuestamente, nos mienten los carabineros en ese instante también, nos dicen sí, sí, les van a dar, si es que ustedes se van entre tales días puede ser que recupere su mercadería, pero no, nunca nos regresan la mercadería, nunca nos han devuelto, nos quitaron, nos quitaron no más. (Hortensia, 33 años, Junio 01 de 2015)

Los costos de las multas muchas veces superan el valor de la mercadería incautada y no asegura su devolución, por lo que algunas prefieren no pagar la multa. Esto configura una doble pérdida, ya que para que puedan recuperar la mercadería, se debe presentar las facturas o boletas de la compra realizada, y si bien la adquisición de la mercadería es legal, no siempre se cuenta con este requisito, porque minimiza el beneficio del ingreso económico.

Hace qué días nos quitó el valor de cuatrocientos dólares, en una feria. Al Miguel le cogieron, no sé cómo pero le cogieron, y le quitaron todo [...] A las diez de la mañana empezamos a vender, pensamos que a las doce ya no van a venir y justo llegaron a las doce los carabineros, y nos llevaron, y nos citaron para las seis, [...] no nos fuimos, mejor le dejamos, porque nos dijo que tenemos que pagar cinco UTM, ni sé cómo esa cosa, y a más de eso, es como valor de doscientos mil pesos nos quitaron, y así como cuatrocientos dólares, yo calculo eso, pero era un poquito más... Algunos nos dicen que igual pagamos, no nos devuelven la mercadería, mejor dejar ahí, pagar multa y encima perder, ino! Mejor ahí, pensamos, luego qué se va a recuperar, esa nuestra idea recuperar solo eso. (Tamia, 32 años, Junio 06 de 2015)

No pagar la multa representa complicaciones de criminalización aún mayores, como la cárcel y para quienes están en condición irregular, hasta la orden de expulsión. De allí que, a pesar de no estar de acuerdo con esta imposición, algunos pagarán el costo. Una estrategia, para que no sea tan alto, consiste en negociar el valor de la multa con el sistema judicial, lo que solo se puede generar a través de un informe social que otorgue la Municipalidad.

Entonces me fui a rogarle a la jueza a que me rebajara la multa, me bajó como a 15 mil pesos, esas son las dos únicas multas que he pagado y eso porque me obligaron [desde que me vino a buscar ya me dio miedo], porque si no, yo no pago. Porque o sea, ya se llevan mis cosas y de ahí tendrían que cobrarse todo, según yo pienso. (Johana, 30 años, Enero 13 de 2015).

Otra consideración es que el pago de la multa está determinado en algunas circunstancias por elementos de la migración: "Es más el maltrato que nos hacen hacia nosotros, que a los propios chilenos" (Gladys, 27 años, Febrero 15 de 2015). 
Retomando el gráfico, se observan otros casos en los que si la persona está indocumentada, los carabineros la trasladan a la comisaría más cercana para además de procesar la multa, notificar a Policía de Investigaciones de la "ilegalidad" de esa persona. Así, a pesar de que la criminalización vivida como comerciante ambulante informal también la presentan los nacionales chilenos que se dedican a esta actividad laboral, los/las inmigrantes viven dificultades que se acrecientan cuando estas mujeres no disponen de visa, temporaria o definitiva, con el riesgo de la deportación.

Pero sí ha sido como ese temor que los carabineros te agarren, te quiten y peor, si de pronto no tienes tus papeles, ahí sí es un problema más grave, pero gracias a Dios nosotros hemos podido sacar nuestra, o sea, nuestro carnet para estar aquí legal, cada uno de nosotros, así ha sido nuestro trabajo aquí, el ámbito laboral. (Johana, 30 años, Enero 13 de 2015)

Además, el maltrato de algunos carabineros hace referencia al origen que se manifiesta en la captura. En este sentido, la interacción con estos funcionarios posiciona a las mujeres trabajadoras en el lugar de una inmigrante delincuente. El trato físico, la forma de procesar la infracción y los insultos que hacen referencia al origen configuran agresiones que dan cuenta que la violencia policial vinculada al círculo de la criminalización, la cual está íntimamente ligada a la violencia simbólica.

Pero he visto, sí, hasta los carabineros, les quitan, les llevan, les pegan, o sea les tratan peor que a un delincuente, pero en realidad, en realidad, no sé, ellos no nos conocen en realidad como somos nosotros. (Gladys, 27 años, Febrero 15 de 2015)

Por ejemplo, nos cogen vendiendo en la calle, nos dicen - por qué no cambian de trabajo- opor qué vienen a trabajar así aquí, por qué no se van a su país-. (Hortensia, 33 años, Junio 01 de 2015)

Bourdieu (2000) señala que las estructuras de dominación son producto de un trabajo histórico de reproducción al que atribuyen unos agentes singulares -que aplican violencia física y simbólica- y unas instituciones, entre las cuales destaca el Estado. De esta manera, se establece una clara relación de poder, la cual no solo irrumpe en la dinámica comercial, sino que afecta las subjetividades de las mujeres, ya que esas acciones amenazantes invaden su área personal.

Igual los carabineros me han tratado mal, así, me han llevado a la comisaría, me han dicho; "te vamos a mandar directo a tu país", así me han dicho, hasta me han hecho llorar, me han dicho "por qué vienes acá, para qué vienes acá", así de todo. Hasta una vez me quisieron quitar mi pasaporte. (Matilde, 23 años, Marzo 13 de 2015)

Si bien la experiencia descrita es la más conflictiva y tensionante, al decir de las mujeres entrevistadas, en los caminos que van recorriendo se configuran mecanismos de asimilación y normalización. Las dificultades vividas en relación con la criminalización se asumen como parte de su vida laboral. A propósito de ello, se puede decir que la violencia simbólica se instituye a través de la adhesión que las mujeres se sienten obligadas a conceder a los funcionarios -dominadores-, asimilando la relación de dominación (Bourdieu, 2000).

Y me empecé a ir con miedo, pero me daba miedo, como ya me han quitado, porque ya he tenido esa experiencia de que me habían quitado mercadería y así me daba miedo... (Rita, 29 años, Febrero 15 de 2015)

(...) teníamos que colocarnos, y de ahí teníamos que salir arrancando pues, teníamos que salir arrancando, pero como tanto estar haciendo uno se acostumbra. Entonces, entra el carabinero, todos dicen "ahí viene carabinero" y salen corriendo, salen arrancando sí. (Nina, 24 años, Junio 05 de 2015)

Esta criminalización se evidencia durante la actividad laboral y, en algunos casos, de quienes no pagan la multa, ocurre en el allanamiento policial: los agentes policiales acuden al domicilio, donde se manifiesta un trato brutal hacia las comerciantes.

Esa fue la peor experiencia, [vinieron a la casa, o sea ya vinieron a buscarte a acorralarte], y eso porque yo estaba estudiando, imagínate si no hubiera estado estudiando, yo tal vez hubiera 
seguido en la cama. Yo estuve ya saliendo al colegio, y me agarraron ahí, cuando ya estaba saliendo para el colegio. Entonces les expliqué, pero no quisieron entender, a ellos no les interesa ninguna razón, nada, ellos solo les interesa que les paguen. (Johana, 30 años, Enero 13 de 2015)

\section{"Empezar de cero"}

Los principios dominantes que se desatan en la relación de fuerza con el campo de poder institucional claramente no pueden ser alterados. Es así como, en los casos entrevistados, "empezar de cero" significa la última e inevitable consecuencia del proceso de criminalización. Las mujeres que no hayan podido escapar de la detención policial o negociar con los/ las funcionarios/as para evitar el decomiso parcial o total de la mercadería, viven una pérdida material. Esto se alía a una pérdida simbólica, es decir, a la motivación por continuar con el trabajo. De allí que es fundamental la presencia de los capitales sociales durante estas circunstancias para las mujeres otavaleñas, puesto que dará cuenta de cómo se retoman las actividades luego de la irrupción, material, simbólica y emocional de su vida laboral.

Bueno, aquí con la familia, mi suegra me prestó un poquito de pañuelos y como doce pañuelos, y con [...] eso yo salí y así de a poquito en poquito empecé nuevamente. Eso, y como mi esposo también estaba haciendo música, me ayudó con poquito de dinero, y con eso ya empecé de nuevo a recuperar mercadería, otra vez ya salía, vendía, ya me iba con mis gastos de mis hijos, del colegio, así, y también compraba mercadería y me iba a vender así de a poquito, así nos ha tocado, empezar de nuevo. (Hortensia, 33 años, Junio 01 de 2015)

La dinámica social y cultural de las otavaleñas detalla formas de relacionarse que se basan en la confianza y mutuo apoyo, elementos que se reproducen igualmente en los momentos que son criminalizadas.

(...) mi hermana como se preocupó en pedir dinero o en prestarme, porque si no, de lo contrario, si yo no tenía quien me ayude yo tenía que quedarme ahí y se truncaría mi estudio por lo menos una semana, tendría que estar igualándome eso, y aparte de eso tendría que estar o sea pasar en la cárcel, y en invierno la cárcel, imagínate está sumamente frío. (Johana, 30 años, Enero 13 de 2015)

Las redes sociales de que dispongan se configuran como un recurso valórico que sostiene la actividad comercial ambulante, puesto que ayuda a su continuidad a pesar de la represión. Por el contrario, aquellas personas que carecían de redes y/o de capital regresan a Ecuador, evidenciando que los recursos disponibles no eran suficientes para sobrevivir.

\section{Estrategias frente a la precariedad: capital cultural y social}

A continuación, se presentan dos formas de constituir estrategias como formas de resistir a la precariedad: la primera, se relaciona con la organización colectiva que algunas de las mujeres están construyendo con sus familias. La segunda, será el análisis del uso del traje típico como una estrategia para la venta, que en el afinamiento de esta hipótesis, sobresale la significación de este elemento identitario para las mujeres entrevistadas.

\section{Capital social: organización cooperativa}

Cuatro de las mujeres entrevistadas pertenecen a una cooperativa de trabajo y las demás forman parte de un grupo sindical recién organizado. Estas dos formas de agruparse dan cuenta de los recursos valóricos sociales con los que cuentan para superar las dificultades individuales a las que se enfrentan en su práctica laboral en Chile. Como complemento, se podría señalar que surgen como manifestaciones de resistencia, en cuanto sostienen un modo de trabajo tradicional y autogestionado frente a la dependencia de un trabajo asalariado. 


\section{Capital cultural: "cuando yo me visto otavaleña, vendo más"}

La literatura sobre las migraciones otavaleñas (Kyle, 2001; Meisch, 2002; Ordóñez, 2008; Ruiz, 2009) advierte que en la adaptación al mundo del mercado, esa carga "exótica" se resignifica como la marca étnica que representa al comercio transnacional vivido a nivel internacional. En Chile, las mujeres entrevistadas manifiestan que esa marca, que ellas la viven en sus cuerpos, es una forma estratégica que facilita la venta. No obstante, también tiene connotaciones más íntimas que harán referencia a su vida cultural y social, que no necesariamente se relaciona con su vida laboral o la instrumentalización del recurso étnico. Así, se entiende el recurso étnico como un capital dinámico, en el sentido de que su valor dependerá del campo en el que se encuentre. En el campo laboral, por ejemplo, significa un beneficio para facilitar las ventas.

Empezamos a vender, [...] como acá, creo que les llama la atención por el traje también, por el traje también, ahora no me pongo yo mucho, pero antes como siempre andaba yo con el traje, como que nos compraban más también, les gustaba hasta la ropa que vendíamos. (Gladys, 27 años, Febrero 15 de 2015)

El vestirse como otavaleña le dará al producto comercializado la caracterización de algo "exótico", que aunque su origen no sea ni artesanal ni ecuatoriano, en relación con la imagen de la vendedora, sí se representa como tal. Por tanto, el venderlo de tal manera para los/las otras/os chilenas/os significarán todas las cargas simbólicas de una artesanía otavaleña, constituyendo la interacción comercial desde esa postura.

Lo que sí me he dado cuenta, es que a la gente sí le gusta la artesanía, le gusta mucho y si es que te ven vestida con la ropa, o sea con nuestra ropa, eh les gusta bastante. Les llama bastante la atención, o sea, nuestros orígenes, todo, ya empiezan a preguntar qué significa esto [...] Y cuando ya estás vendiendo te dicen "iesto es de Ecuador? (Johana, 30 años, Enero 13 de 2015)
En la interacción que se entabla entre la vendedora y su posible comprador, este capital étnico en el campo cultural, asume una condición de identidad y pertenencia, lo cual se construye en la reafirmación.

La verdad es un orgullo, tener como ser otavaleñas, tener el traje que nosotros tenemos, porque en verdad por personas que ven $y$ les gusta conocer, es como 'oh, wow, ustedes tienen su tradición', y es muy bueno que lo puedan llevar. Entonces, es muy bonito poder indicar a otras personas de que nosotros tenemos así y podemos trabajar de esa manera. No tenemos por qué esconder nuestra esencia de ser indígenas. (Gina, 21 años)

Visto así, el uso del traje asume dos connotaciones: una, representa un beneficio para facilitar las ventas y otra, que está en el lado íntimo de la identidad, donde la significación está construida en el orgullo de pertenecer a una cultura y lugar en particular. El énfasis, los asentamientos y las risas dan cuenta de que, al considerar el tema de la vestimenta, las mujeres reafirman y merman las dificultades. Por lo tanto, la marca se configura como un capital que se reconoce que se utiliza y restituye en los procesos de comercio transnacional que viven las/os otavaleñas/os a nivel mundial.

\section{Discusión}

El comercio callejero ambulante en Chile se caracteriza por riesgo, conflicto y precariedad, dificultades que son vividas por locales y migrantes que se dedican a esta actividad comercial. No obstante, aquellos que la viven bajo una condición migratoria (regular o irregular) sumarán percances relacionados con el acceso a permisos municipales y, en lo relacional, a la discriminación por origen, raza y género, con lo cual parecería que están condenados a un "malabarismo incesante" (Bourdieu, 1999). El trabajo ambulante además de estar bajo condiciones informales (inferioridad estructural de total desprotección), es un campo que está normado y deshumanizado, donde lo informal se 
encuentra en un nivel jerárquico inferior a la estructura de la formalidad.

Para las otavaleñas, el trabajo ambulante representa una expectativa simbólica que puede significar ascensión social, al configurarse en una tradición anudada al comercio internacional. Sin embargo, al situarse en el campo de trabajo callejero, la trayectoria social se instrumentaliza y se considera una práctica únicamente ligada a la sobrevivencia. Las mujeres otavaleñas que se vinculan a este sector pertenecen a una clase que sobrevive el trabajo, forman parte del grupo más empobrecido de otavaleños/as en Chile y desde esa posición organizan y trazan su práctica laboral. Frente a estas dificultades, construyen estrategias, tanto sociocomunitarias como individuales que además de facilitar las ventas les permiten superar las dificultades vividas en el campo laboral callejero.

Otra estrategia observada, específicamente en las mujeres, se refiere a la instrumentalización de la vestimenta típica; esto es, que se reconoce una mayor venta cuando más se utiliza, lo que da cuenta de que en el mercado capitalista persisten elementos que, además de definir su ser como mujeres otavaleñas -carga cultural incorporada-, facilitan las relaciones comerciales. Aun así, el intercambio sociocultural con los/las nacionales chilenos en la dialéctica comercial significa tomar el espacio público, exponer un origen, una cultura y una forma de vida. De este modo, se configura como una táctica para sobrevivir, que a su vez juega como resistencia a la asimilación. De allí que el uso de la vestimenta otavaleña no representa una adaptación al capitalismo, ni un arraigo "naturalizado" a la cultura, sino más bien a una dinámica de una forma de vida cargada de significantes. Una forma de intercambios, no solo económicos sino simbólicos, donde los códigos de la cultura se ponen en juego en el campo del comercio.

Entre las limitaciones del estudio podemos señalar las siguientes: no se realizó un acompañamiento en espacios de conflicto con la Policía, no obstante, se llevaron a cabo algunos trayectos comentados. Otra, fue no acceder al recorrido de las participantes a otras ciudades de Chile, aspecto que se requiere indagar en un futuro estudio. Además, dado que la temática es nueva, se considera indispensable desarrollar un estudio comparativo con otras realidades de América Latina. Por último, sería interesante incorporar la visión transnacional en la metodología, para explorar el proceso migratorio desde Otavalo.

\section{Agradecimientos}

Agradezco a todas las mujeres otavaleñas que, con sus narrativas y compartir, ayudaron a desarrollar esta investigación. Además a María Emilia Tijoux, guía clave y referente de los estudios sobre las migraciones en Chile.

\section{Referencias}

Antunes, R. (2009). Diez tesis sobre el trabajo del presente (y el futuro del trabajo). En J. Neffa, E. De la Garza \& L. Muñiz (Comps.), Trabajo, empleo, calificaciones profesionales, relaciones de trabajo e identidades laborales (pp. 29-44). Buenos Aires: CLACSO.

Bourdieu, P. (1995). Sociología y cultura. México: Grijalbo.

Bourdieu, P. (1999). La miseria del mundo. Madrid: Akal.

Bourdieu, P. (2000). Poder, derecho y clases sociales. Bilbao: Desclée de Brower.

Bourdieu, P. (2001). ¿Qué significa hablar? Madrid: Akal.

Cabieses, B., Bernales, M., \& Mcltyre, A. M. (2017). La migración internacional como determinante social de la salud en Chile: evidencia y propuestas para políticas públicas. Santiago de Chile: Universidad del Desarrollo.

Camacho, G. (2010). Mujeres migrantes: trayectoria laboral y perspectiva de desarrollo humano. Buenos Aires. CLACSO.

Cano, V., \& Soffia, M. (2009). Los estudios sobre migración internacional en Chile: apuntes y comentarios para una agenda de investigación actualizada. Papeles de Población, 15(61), 129-167. Recuperado de http://www.scielo.org.mx/scielo.php?script 
$=$ sci_arttext\&pid $=\mathrm{S} 1405-742520090003$ $0000 \overline{7}$

Chile, Decreto 1881 de 2009 [Municipalidad de Santiago]. Modifica la Ordenanza N. ${ }^{\circ}$ 59 de 1994 sobre el comercio estacionado y ambulante de bienes nacionales de uso público. Noviembre 24 de 2009. Recuperado de http://www.leychile.cl/Nav egar?idNorma $=241792 \mathrm{\#}$

Contreras, D., Ruiz-Tagle, J., \& Sepúlveda, P. (2013). Migración y mercado laboral en Chile (Serie Documentos de Trabajo de la Facultad de Economía de la Universidad de Chile N. ${ }^{\circ}$ 376). Santiago de Chile: Universidad de Chile.

Da Rosa, S., Chafin, M., Baasch, D., \& Soares, J. (2011). Sentidos y significados del trabajo: un análisis con base en diferentes perspectivas teóricoepistemológicas en psicología. Universitas Psychologica, 10(1), 175-188. Recuperado de http://revistas.javeriana.edu.co/index.p hp/revPsycho/article/view/415/790

De la Garza, E. (2000). Tratado latinoamericano de sociología del trabajo. México: El Colegio de México.

FUNDACIÓN CREA. (2015). Experiencia migratoria de la población ecuatoriana en Chile: identificación, caracterización y empoderamiento para el despliegue de los migrantes ecuatorianos en redes comunales. Manuscrito inédito.

Goffman, E. (1963). Estigma. La identidad deteriorada. Buenos Aires: Amorrortu.

Ghersi, E. (agosto, 2005). La economía informal en América Latina. Recuperado de http://www.elcato.org/la-economia-info rmal-en-america-latina

Kyle, D. (2001). La diáspora del comercio otavaleño: capital social y empresa transnacional. Ecuador Debate, 54, 85-110. Recuperado de http://hdl.handle.net/1046 9/4892

Lafleur, J. M., \& Yépez, I. (2014). Transnacionalismo y circulación migratoria: dos visiones para pensar el vínculo entre migración y desarrollo. En G. Herrera (Ed.), El vínculo entre migración y desarrollo a debate: Miradas desde Ecuador y América Latina. (pp. 71-94). Quito: FLACSO Ecuador.

Maldonado, G. (2004). Comerciantes y viajeros. De la imagen etnoarqueológica de "lo indígena" al imaginario del kichwa Otavalo "universal". Quito: FLACSO/Abya Yala.

Martínez, J. (2003). El encanto de los datos. Sociodemografía de la inmigración en Chile según el censo de 2002 (Serie Población y Desarrollo N. ${ }^{\circ} 49$ ). Santiago: CEPAL/CELADE. Recuperado de https://www.cepal.org/es/publicaciones/ 7187-encanto-datos-sociodemografia-la-in migracion-chile-segun-censo-2002

Martínez, J. (2016). La migración internacional y la protección de los derechos de todas las personas migrantes. En X. Erazo, J. Esponda \& M. Yaksic (Eds.), Migración y derechos humanos: mediación social intercultural en el ámbito local (pp. 39-70). Santiago de Chile: Lom Ediciones/Fundación Henry Dunant América Latina.

Meisch, A. (2002) Andean entrepreneurs: Otavalo merchants and musicians in the global arena. Austin: University of Texas Press.

Mora, C. (2009). Estratificación social y migración intrarregional: algunas caracterizaciones de la experiencia migratoria en Latinoamérica. Recuperado de http://www.scielo.cl/scielo.php?script $=$ s ci_arttext\&piS0718-23762009000100008

Organización Internacional para las Migraciones. (2012). Panorama migratorio de América del Sur 2012. Buenos Aires: Autor. Recuperado de https://www.iom.int/files/live/sites/iom/f iles/pbn/docs/Panorama_Migratoriode_A merica_del_Sur_2012.pdf

Organización Internacional del Trabajo (2014). Panorama temático laboral: transición de la formalidad en América Latina y el Caribe. Lima: OIT

Organización Internacional del Trabajo OIT (2016). Panorama laboral2016: América Latina y el Caribe. Lima: OIT

Ordóñez, A. (2008). Migración transnacional de los kichwa Otavalo y la fiesta del PawkarRaymi. En A. Torres \& J. Carrasco 
(Eds.), Al filo de la identidad: la migración indígena en América Latina (pp. 69-88). Quito: FLACSO Ecuador.

Pedone, C. (2004). Tú siempre jalas a los tuyos. Cadenas y redes migratorias de las familias ecuatorianas hacia España (Tesis doctoral inédita). Universidad Autónoma de Barcelona.

Portes, A., Guarnizo, L.,\& Landolt, P. (2003). El estudio del transnacionalismo: peligros latentes y promesas de un campo de investigación emergente. En A. Portes, L. Guarnizo \& P. Landolt (Coords.). La globalización desde abajo: transnacionalismo inmigrante y desarrollo. La experiencia de Estados Unidos y América Latina (pp. 15-44). México. FLACSO/Miguel Ángel Porrúa.

Portes, A., \& Haller, W.J. (2004). La economía informal. Santiago de Chile: CEPAL.

Portes, A., \& DeWind, J. (2006). Un diálogo transatlántico: el progreso de la investigación y la teoría en el estudio de la migración internacional. En A. Portes \& J. DeWind (Coords), Repensando las migraciones: nuevas perspectivas teóricas y empíricas (pp.157-190). México: Miguel Ángel Porrúa/Universidad Autónoma de Zacatecas/Secretaría de Gobernación, Instituto Nacional de Migración.

Ramírez, F., \& Paul, J. (2005). La estampida migratoria ecuatoriana. Crisis, redes transnacionales y repertorios de acción migratoria (2.a.ed.). Quito: Centro de Investigaciones CIUDAD. Recuperado de http://biblioteca.clacso.edu.ar/Ecuador/ ciudad/20121009105948/ramirez.pdf

Ruiz, A. (2005). Espacios migratorios transnacionales: la emergencia de un nuevo contexto para las políticas públicas. En J. González \& M. Setién (Eds.), Diversidad migratoria: distintos protagonistas, diferentes contextos (pp. 95-108). Bilbao: Universidad de Deusto.

Ruiz, A. (2009). La migración otavaleña: un caso de transnacionalismo precoz. Leioa, Bizkaia: Ikuspegui-Observatorio Vasco de Inmigración. Recuperado de http://www.ikuspegi-inmigracion.net/do cumentos/fondoikus/migracionotavala_cas .pdf

Stefoni, C. (2004). Inmigrantes transnacionales: la formación de comunidades y la transformación en ciudadanos. En U. Berg $\&$ K. Paerregaard (Coords.), El quinto suyo, transnacionalidad y formaciones diaspóricas en la migración peruana (Cap. 9). Lima: Instituto de Estudios Peruanos.

Stefoni, C. (2011). Ley y política migratoria en Chile: la ambivalencia en la comprensión del migrante. En B. Feldman-Bianco et al. (Comps.), La construcción social del sujeto migrante en América Latina: prácticas, representaciones y categorías (pp. 79-110). Quito: CLACSO/FLACSO/ Universidad Alberto Hurtado.

Stefoni, C., Acosta, E., Gaymer, M., \& CasasCordero, F. (2008). Niños y niñas inmigrantes en Santiago de Chile: entre la integración y la exclusión. Santiago de Chile: Universidad Alberto Hurtado/OIM.

Suárez, L. (2008). Lo transnacional y su aplicación a los estudios migratorios: algunas consideraciones epistemológicas. En E. Santamaría (Coord.), Retos epistemológicos de las migraciones transnacionales (pp. 55-78). Madrid: Anthropos.

Tijoux, M. (2011). Negando al 'Otro'. El constante sufrimiento de los inmigrantes peruanos en Chile. En C. Stefoni (Comp.), Mujeres inmigrantes en Chile iFuerza de trabajo o mujeres con derechos? (pp. 17-42). Santiago de Chile: Universidad Alberto Hurtado.

Villamar, D. (2004).Características y diferencias clave entre las primeras migraciones y la reciente o la emigratoria. Cartillas sobre Migración N..$^{\circ}$ 10. Plan Migración, Comunicación y Desarrollo. Disponible en http://www.fes-ecuador.org/media/pdf/ migracion10.pdf

\section{Notas}

* Artículo de investigación 